\title{
Turizm Tarihi İncelemelerinin Yaygınlaşması Neden Önemlidir?
}

\section{Giriş}

Turizm tarihi, özel ilgi alanı gibi görülse de, sosyal bilimlerin tarihselliği gereği son derece önemlidir. Tarihin temelinde özetle, bugünün geçmişin ürünü olduğu ve tarih araştırmalarının geleceğe 1şık tutabileceği düşüncesi yatar. Sosyal bilimlerin tarih ile bir anlamda iç içe doğup sonradan ayrışmasına karşın, son yıllarda tekrar yakınlaşması sürecinde turizmin de yerini ald1ğını söylemek zordur. Turizm araştırmalarının çoğunlukla mevcut zamana ve geleceğe odaklı olduğu söylenebilir. Bu çalışmada, turizmin gelişiminde turizm tarihinin önemi sosyal bilimler temelinde ve kendi disipliner gelişimi açısından ele alınacaktır.

\section{Tarih ve Sosyal Bilimler}

İnsanoğlu, yaklaşık 100.000 yıl önce Afrika'dan kuzeye ve sonra tüm kıtalara doğru yayılmaya başladı. Yiyecek bulmak, korunmak, ticaret amaçlı insan hareketliliğine, Antikçağ ile birlikte ticarete ek olarak merak (Zuelow 2015), keyif ve "seyahat etmek için seyahat etmek" (Löschburg 1998) eklendi. İş/ticaret, keyif ve merak amaçlı seyahatler biçim değiştirerek günümüze kadar devam ederken, halâ başlıca seyahat nedenleridir.

Tarihin kurucu ismi kabul edilen, Halikarnassos'lu Heredotus'un (M.Ö. 484-425) aynı zamanda ülkesinin ilk gezginlerinden olmasi ilginç bir tesadüftür. Heredotus, doğal dünyada olduğu gibi, insan topluluklarına dair bilinebilir tüm bilginin araştırılması ve kaydedilmesini ifade eden historia fikrini ilk ortaya atan kişi olarak kabul edilir. Heredotus Atina'dan Sicilya'ya, Medler'in başkenti Ekbatana'ya, Karadeniz'in kuzey kiyılarına ve Misır'a giderek, seyahati boyunca elde ettiği bilgi, efsane ve mitlere kendi düşüncelerini de ekleyerek on ciltlik Tarih adlı eserini yazd1 (Löschburg 1998).

Historia düşüncesi 17. yy. sonlarına kadar devam etmiş ve bu dönemden sonra tarih, sadece insanî ve toplumsal olaylar olarak ele alınmıştır (Özlem 2012). Sosyal bilimler ve tarih ilişkisi, sosyoloji veya daha genel olarak sosyal bilimler düşüncesini ilk kez ortaya İbni Haldun (1332-1406) tarafından da dile getirilmiştir. İbni Haldun, umran adını verdiği yeni bir bilim alanı ile toplumsal hayatın ve örgütlenmesinin ortaya çıkardığ 1 her türlü toplumsal olay, grup ve kurumların incelenmesiyle, bazı değişmezlerin saptanabileceğini savunmuştur. Bu açıdan, umran ile tarih yakın ilişkilidir. İbni Haldun'un tarih yaklaşımına göre, önemli olayların ve kişilerin hayatının aktarılmasından farklı olarak, her türlü toplumsal, ekonomik, dinî, bilimsel, kültürel vd. olaylar aç-sından ele alınarak, nedensel ilişkiler içinde incelenmeli ve açıklanmalıdır. Buna göre, öncelikle yapılacak olan tarih araştırması, umran bilimi için gerekli modellemeleri, nedensel açıklamaları sağlayacaktır (Arslan 2017). İbni Haldun'dan sonra toplum bilimleri düşüncesi, 18.yy.'a kadar uzun bir süre keşfedilmeyi bekleyecektir.

18. ve 19. yüzy1llar, sosyal bilimler düşüncesinin kurumlaşmaya başladığı dönemdir. Tarih ise 19.yy.'da, hükümdarların, önemli olayların öykülenmesinden, "gerçekte ne olduğunu" inceleyen bir bilim alanı haline gelmekte ve sekülerleşmektedir. Aristoteles'ten (M.Ö. 384-322) beri devam eden, insan doğasının değişmez olduğu görüşüne karşın, Giambattista Vico (1668-1744), 
insanın doğasının dinamik olduğunu, insanın doğası ve insan topluluğunu anlamak için tarihsel gelişimi içinde ele almak gerektiğine işaret etti. Montesquie'ya (1689-1755) göre de toplumsal kurumlar, süreçler ve ilişkiler ampirik ve tarihsel analizle keşfedilebilirdi. Sosyal bilimlerin tarihselliği, sosyolojinin kurucu ismi Aguste Comte (1798-1857) tarafından da dile getirilir. Comte, toplumun statik yapısının karşılaştırmalı analizle, dinamik yapısının ise tarihsel analizle incelenebileceğini ileri sürdü (Swingewood 2010).

Sosyal bilimlerin kurucu isimlerinin hemen hepsi, kuramlarını tarihle ilişkili olarak ele alırlar. 18.yy.'dan beri devam eden sosyoloji ve tarihin birlikteliği, 20. yy.'ın ilk çeyreğinde ayrılır. Bunun nedenleri arasında, tarihçilerin sosyologları fazla indirgemeci, sosyologların da tarihçileri genel örüntüyü görmezden gelmeleri (Toprak 2015), özellikle sosyal bilimlerdeki pozitivist eğilimler gibi eleştiriler (Karabağ 2015) sayılır. Diğer yandan, 20.yy.'ın ilk yarısında, başta fizik olmak üzere bilimde görelilik düşüncesi, diğer bilim alanlarında olduğu gibi tarihte de nesnelliğin sorgulanmasına neden olmuştur. Tarihte nesnelliğin sorgulanmasında siyasî tarih yazımının etkisinin olduğu da söylenebilir. Bugün gelinen noktada, tarihte postmodern yorum ile klasik yaklaşımın görece dengeli biçimde devam ettiği görülmektedir (Durgun 2019).

Sosyal bilimler ile tarih, başta sosyoloji olmak üzere 1960'lı yıllardan itibaren tekrar yakınlaşmaya başlamıştır (Gülbenkian Komisyonu 2011). Bu yakınlaşmada, 20.yy.'in ilk yarısında ortaya çıkan sosyoloji, antropoloji, coğrafya, ekonomi gibi çeşitli toplumbilimleri ile birlikte ele alınan tarih anlayışına dayalı Annales Okulu'nın etkisinden de söz edilebilir. Diğer yandan, 1980'ler ve sonrasinda sosyal bilimlerde otomasyona dayalı veri işleme imkânlarının gelişmesi ve araştırma eğilimlerine olan etkisi (Klein 2018) söz konusu yakınlaşmanın tekrar yavaşlamasına neden olmuş görünmektedir.

Tarih ile sosyal bilimler arasındaki gel-git ilişkileri devam etse de kabul edilen bir gerçek vardır ki o da sosyal bilimler özünde tarihseldir (Reau 2014). Sosyal bilimlerin tarihe gereksinimi kadar, tarihin de farklı disiplinlerin kavramlarına, tema- larına ihtiyacı vardır (Klein 2018). Modern sosyal bilimi, güncel veri analizine dayalı olmakla da eleştiren Hobswan (2001), Tarih Üzerine adlı eserinde, "geçmişin insan bilincinin sürekli bir boyutu, insan toplumunun kurumların, değerlerin ve diğer kalıpların kaçınılmaz bileşeni" olduğunu söyler. Şimşek'e (2015) göre ise "tarih, geçmişten bugüne yaşanmış olay, kişi, kurum, kültür, düşüncenin izini sürerek bir anlamda meydana gelen değişimleri, bugüne kadar var olan sürekliliği inceler". Tanımlardan görüleceği gibi tarihin ortak noktasında geçmişten yola çıkarak bugünü anlama düşüncesi bulunmaktadır.

\section{TARIH VE TURIZM}

Yukarıda anılan gelişmelerle karşılaştırıldığında, turizm tarihle yakınlaşmadaki yerini daha geç almaktadır. Turizmle ilgili çalışmalar bilindiği gibi 20.yy.'ın başında başlamış olsa da, akademik bir disiplin olarak kabul edilmesi 1920'lerden sonradir. 1990'lardan itibaren ise turizmin olgun bir disiplin haline gelmeye başladığı görülür (Kozak ve Kozak 2016). Turizm, güçlü sosyoloji, tarih ve antropoloji gibi kökenleri bulunsa da daha çok ekonomi ve işletme temelinde gelişmesi ve ana akım araştırma paradigmalarının etkisiyle farklı bir gelişim göstermiştir. Bunun nedenleri arasında, kalkınma ve refah artışında turizmin ekonomik öneminin dikkat çekmesi ve özellikle, 1970'lerden sonra, veri odaklı araştırmaya ve İngilizce dergilerde yayın yapmaya ilginin artması (Kozak ve Kozak 2016) sayılabilir. Turizm günümüzde uluslararası akademik alanda kurumsallaşmış bir disiplin olarak kabul edilse de, turizm tarihi araştırmacılarından Walton (2011) turizm araştırmalarında temel bir sorun olarak "mevcut zamana odaklılık" ve "yüzeysellik" şeklinde daha sert bir eleştirir getirir.

Öte yandan, tarih araştırmacıları da turizm ve seyahat olgusuna çok fazla ilgi göstermemişlerdir (Walton 2011). Oysa ki, dünya tarihinde pek çok önemli dönüşümün seyahatler aracılığg ile gerçekleştiğini görmek mümkündür. Milet'li Thales'in (M.Ö. 624-545) Misir seyahatlerinden etkilenerek ilk felsefî fikirleri ortaya atması, İpek Yolu'nun sadece ticaret ile kalmayarak özellikle Doğu'nun gizemli dünyasını keşfetme isteğini 
arttırması, 15.yy.'dan sonraki Keşifler Çağı'nda deniz seyahatlerinin dünyaya dair bilinenleri tamamen değiştirmesi ve merak duygusunu arttırması, sanat ve bilimle uğraşanların İtalya ve Fransa gibi merkezlere seyahatleri ve buradaki etkileşimlerinin Rönesans ve Aydınlanma'ya etkileri gibi keşif, ticaret, öğrenme amaçlı seyahatlerin dünyada bilim, sanat, düşünce ve kültür dönüşümüne pek çok örnek vermek mümkündür. Özellikle, doğa bilimleri ve antropoloji bilimlerinin gelişmesinde bu keşif ve seyahatlerin büyük etkisi olmuştur (Gülbenkian Komisyonu 2014).

Turizm, Antik Çağ'da ve daha sonra Rönesans'tan beri kültürel yaşamın önemli bir parçasıdır (Towner 1995). Ancak Towner (1995), turizm tarihi çalışmalarının genellikle Avrupa odaklı olmasını, çoğunlukçu yaklaşımla büyük ve ölçülebilir veriler çerçevesinde ele alınmasını, birbirinden kopuk ve sadece elit kesimin ve prestijli hareketlerin incelenmesine yoğunlaşmasına dikkat çeker. Bu nedenle, turizm tarihi bir süreklilik içinde olmayan, sadece belli tarihsel koşullar içinde bilgi vermeye yöneliktir. Örneğin, Grand Tour'la ilgili çokça malûmata karşılık, 18.yy.'dan sonra ne olduğu, farklı bir turizm biçimine evrilip evrilmediği pek fazla ilgi çekmemektedir. Turizm tarihi ile ilgili bilgiler genellikle Antik Çă̆'daki ilk hareketler, Orta Çağ'da dinî seyahatler, Grand Tour, Endüstri Devrimi'nin etkileri gibi belli dönemler içinde ele alınır. Kapsamlı tarih araştırmaları aslında turizmde bazı eğilimlerin çok daha eskiye gittiğini göstermektedir. Örneğin, Roma döneminde de Grand Tour benzeri Atina'ya eğitim seyahatleri yapılmaktaydı (Löschburg 1998).

Benzer biçimde, insanlığın ilk ortak anlatı ürünü olan mitlerde de seyahat olgusuna sik rastlanır. Levi-Strauss'a (2013) göre, mitler insanların kavramsal düşüncelerini ve dünya görüşlerini yansıtan veri kaynaklarıdır ve mitlerdeki olaylar, temalar, kişiler o dönem insanların düşüncelerini ve modellerini yansıtır. Dünyanın ilk yazılı miti Sümerler'e ait olan ve M.Ö. 2. bin yılda yazıya geçirilen Gılgamış Destanı'nda, Ur şehrinin her şeye muktedir kralı Gılgamış'ın, kahramanlık, ölümsüzlük ve gençlik gibi arayışlarla seyahate çıkması, kimilerince ilk turist tipi örneğidir (Battilani vd. 2016).
Dünyanın en büyük ve dinamik sosyal olgularından biri olarak turizm, sosyal bilimler ve tarih temelinin görece zayıf bağlantılar içinde ele alınması eğilimi son yıllarda değişmektedir (Walton 2009, 2005). "Tarih, turizme ne kazandırabilir ?" sorusuna Walton (2009), "geçmiş olayların, geçmişteki algıların ve eğilimlerin bugün nerede olduğumuz ve gelecekte nereye yöneleceğimiz konusunda son derece önemli katkıları olacaktır" yanıtını verir.

Turizm tarihinin son yıllarda önem kazanması çeşitli platformlarda da kendini göstermiştir. 2009 yilında yayına başlayan Journal of Tourism History dergisinin 2016 yılındaki yayınlanan bir sayısında, turizm tarihi araştırmacıları için özel bir tartışma bölümüne yer verilmiştir. Öne çıkan görüşler arasında, turizmin özellikle kültür tarihi açısından cazip bir alan olduğu, turizm tarihinin özellikle kültür ve miras turizmi ile birlikte önem kazandığ 1 , turizmin genel olarak toplum tarihinin bir parçası olduğu, turizm tarihinde özellikle modern dönem öncesi tarihsel sürekliliğin bulunmayışı, küreselleşmede turizmin etkileri yer alır (Battilani vd. 2016).

Özellikle, önemli bir sosyal olgu olarak turizm gibi son yıllarda olgunlaşmış, disiplinlerarası nitelikli bir alanda tarihsel inceleme, önceki eğilimlerin, uygulamaların, süreçlerin, varsayımların tarih içinde nasıl dönüştüğünün anlaşılması için önemlidir. Bu tür araştırmalar sadece bulunduğu tarihsel bağlamı anlamakla sinırlı kalmayıp, günümüzle karşılaştırmalı olarak ele alındığında, kritik değerlendirmeler yapilabilir. Turizm tarihi, günümüzdeki ana akım çalışmalarından farklı olarak, turizmin kültür, antropoloji, sosyoloji, edebiyat, kültürel coğrafya (Walton 2005), estetik, bilim, teknoloji, politika, çevre (Zuelow 2015; Wall 2003) gibi farklı disiplinlerle incelenerek zenginleşmesini sağlayacaktır. Ayrıca, sınırlı bir turizm olgusundan ziyade boş zaman, rekreasyon, seyahat kavramlarının birlikte ele alınması yararlı olacaktır (Towner 1995). Turizm tarihiyle ilgili detaylı araştırmalar, fazla basite indirgenmiş söylemlerin tekrarlanmasını da önlerken (Walton 2011), çağdaş turizmin ve modellerinin nasıl geliştiği daha derinlemesine anlaşılmasını da sağlayacaktır (Holden 2005). 
Dünya'da turizm tarihi araştırmalarına ilgi artarken (Örneğin; Towner 1995; Löschburg 1998; Walton 2005, 2009, 2011; Zuelow 2015, Battilani vd. 2016), endüstrileşmeye bağlı olarak turizm tarihi kaynaklarının özellikle Büyük Britanya'da yoğunlaştığı görülür. Türkiye'de farklı yayın türlerinde bazı turizm tarihi çalışmaları bulunsa da (Örneğin; Türk Turizm Tarihi, 2013, Ed. Ş. Çavuş, Z. Ege ve O. E. Çolakoğlu) henüz çok fazla yol alınmadığı görülmektedir. Anadolu Üniversitesi Bilimsel Araştırma Projesi kapsamında, Prof. Dr. Nazmi Kozak koordinatörlügünde yürütülen Türkiye Turizmi Sözlü Tarih Araştırması'nın (2012-2016) mevcut halde en kapsamlı turizm tarihi çalışması olduğu söylenebilir. Diğer yandan, son yillarda giderek artan turizmde bibliyometri çalışmalarının, disiplin tarihi açısından katkı sağlayan çalışmalar olduğunu söylemek mümkündür.

\section{SONUÇ YERINE}

Auguste Comte (1896), bir bilimi anlamanin en iyi yolunun, onun tarihini anlamak olduğunu ileri sürer. Bu açından, turizmde henüz gerekli doygunluğa erişildiğini söylemek zordur. Turizmin daha sağlıklı bir sosyal bilim olarak gelişmesinde tarih araştırmalarının önemi açıktır. Tarih araştırmalarında dikkat edilmesi gereken başlıca konular konu, dönem, coğrafi sınırlar ve tarih yaklaş1minın (sosyal, kültürel, ekonomi, biyografi, karşılaştırmalı tarih, sözlü tarih vb.) belirlenmesidir (Talbot 2015). Turizmin hem zenginliğini, hem de zorlayıcı yönünü oluşturan disiplinlerarası özelliği gereği, seyahatnameler hariç tutulduğunda, doğrudan ilgili kaynaklara erişmek kolay olmayabilmektedir. Turizm tarihi araştırmacılarının, genellikle farklı amaçlarla oluşturulmuş tarih kaynakları arasında ilgili verilere erişmesi için, kimi zaman âdeta kazı çalışması yapması gerekebilir. Sadece turizm değil, tarih için de çok önemli veri kaynakları olan seyahatnamelerin ise öznelliği, seyahat amacı (Şirin 2015), dönemin anlatı geleneği gibi boyutları dikkate alınarak titizlikle incelenmesi önerilir. Bu şekilde, tarih araştırmaları, turizm bilgi birikimini zenginleştirirken, günümüzdeki çalışmaların daha nitelikli ve derinlemesine açıklanmasını destekleyecektir.

\section{KAYNAKÇA}

Arslan, A. (2017). İbni Haldun. İstanbul: İstanbul Bilgi Üniversitesi Yayinları.

Battilani, P., Gordon, B.M., Furnee, J.H., James, K.J., White, R. ve Zuelow, E. G. E. (2016). Discussion: Teaching Tourism History, Journal of Tourism History, 8 (1): 57-84.

Comte, A. (1896). The Positive Philosophy, https://socialsciences.mcmaster.ca/econ/ugcm/3ll3/comte/Philosophy1.pdf, (Erişim Tarihi: 10 Şubat 2020),

Çavuş, Ş., Ege, Z. ve Çolakoğlu, O.E. (Ed.). (2013). Türk Turizm Tarihi. Ankara: Detay Yayıncılı.

Durgun, F. (2019). Nesnellikten Postmodernizme Profesyonel Tarih Yazımı. İçinde: Ahmet Şimşek (Ed.) Tarih Nasıl Yazılır (ss.15-28) Ankara: Kuban Matbaacilık.

Gülbenkian Komisyonu. (2014). Sosyal Bilimleri Açın. İstanbul: Metis Yayınları.

Hobsbawn, E. (2001). Tarih Üzerine. Ankara: Bilim ve Sanat Yayınları.

Holden, A. (2005). Tourism Studies and the Social Sciences. Londra: Routledge.

Karabağ, G. (2019). Disiplinlerarası Tarih Çalışmaları. İçinde: Ahmet Şimşek (Ed.) Tarih Nasıl Yazılır (ss.149-176) Ankara: Kuban Matbaacilik.

Klein, H. (2018). The "Historical Turn" in the Social Sciences, Journal of Interdisciplinary History, XLVIII (3): 295-312.

Kozak, M. ve Kozak, N. (2016). Institutionalisation of Tourism Research and Education: From the Early 1900s to 2000s, Journal of Tourism History, 8 (3): 275-299.

Levi-Strauss, C. (2013). Mit ve Anlam. İstanbul: İthaki Yayınlar1.

Löschburg, W. (1998). Seyahatin Kültür Tarihi. Ankara: Dost Kitabevi Yayınları.

Özlem, D. (2012). Tarih Felsefesi. İstanbul: Notos Yayınevi.

Reau, B. (2014). The Historical Social Science of Tourism, Journal of Tourism History, 6 (2-3): 210-222.

Swingewood, A. (2020). Sosyolojik Düşaüncenin Kısa Tarihi. İstanbul: Agora Kitaplığı.

Şimşek, A. (2015). Tarihsel Zaman, Değişim ve Süreklilik. İçinde: Ahmet Şimşek (Ed.) Tarih İçin Metodoloji (ss. 8-11) Ankara: Pegem Akademi.

Şirin, İ. (2015). Seyahatname, Hatırat ve Mektup. İçinde: Ahmet Şimşek (Ed.) Tarih İçin Metodoloji (ss. 263-272) Ankara: Pegem Akademi.

Talbot, M. (2015). Tarihçi Gibi Araştırmak. İçinde: Ahmet Şimşek (Ed.) Tarih İçin Metodoloji (ss. 216-220) Ankara: Pegem Akademi.

Toprak, Z. (2015). Sosyal Tarih. İçinde: Ahmet Şimşek (Ed.) Tarih İçin Metodoloji (ss. 110-115) Ankara: Pegem Akademi.

Towner, J. (1995). What is Tourism History, Tourism Management, 16 (5): 339-343.

Wall, G. (2003). Perspectives on Temporal Change and the History of Tourism and Recreation. İçinde: C. Cooper (Ed.) Classical Reviews in Tourism (ss. 55-76). Clevedon: Channel View Publications 
Walton, J. K. (2005). Introduction. İçinde: J. K. Walton (Ed.) Histories of Tourism: Representaton, Idendity and Conflict (ss.1-18). Clevedon, Buffalo: Channel View Publications.

Walton, J.K. (2009). Prospects in Tourism History: Evolution, State of Play and Future Developments, Tourism Management, 30: 783-793.

Walton, J.K. (2011). Tourism and History. Oxford: Goodfellow Publishers Ltd.
Zuelow, E. G. (2015). A History of Modern Tourism. Londra: Palgrave.

Dilek ACAR, Doç. Dr., Anadolu Üniversitesi Yunus Emre Kampusu Eskişehir Meslek Yüksekokulu, 26470, Eskişehir

ORCID: 0000-0002-2683-6004

E-posta:dacar1@anadolu.edu.tr 